\title{
A TWO-SYRINGE METHOD FOR EXCHANGE BLOOD TRANSFUSION
}

\author{
BY \\ P. LAZARUS-BARLOW \\ From the Royal East Sussex Hospital, Hastings
}

(RECẸIVED FOR PUBLICATION AUGUST 13, 1949)

Exchange blood transfusion in cases of erythroblastosis foetalis is now an accepted form of treatment but a somewhat tedious one, especially if it has to be carried out in the early hours of the morning. It was, therefore, decided to try and see whether the time could be cut down by using two syringes, whereby blood was withdrawn from the infant into one while the other was being charged with blood from the bottle. The infant thus receives blood for every complete excursion of the piston intead of once in every two.

The illustration explains itself. A glass Y-piece with short rubber tubing and adaptor connects the needle from the umbilical catheter by two pieces of pressure tubing 5-6 in. long to the two syringes, one of which is connected to the bottle of blood and the other to the receptacle for the withdrawn blood. The syringes are of the Louis Jubé $5 \mathrm{ml}$. type, but any syringes with suitable two-way taps may be used. The great advantage of the Jubé syringe is that the alteration in the direction of flow is made by turning the piston through $180^{\circ}$ and the hand does not have to be removed to turn a small tap. This is a time-saving measure.

A trial in the laboratory showed that with a little practice two people soon could work in unison, and the method has now been tried in a small number of cases with success. The time taken to transfuse about $450 \mathrm{ml}$. of blood is approximately 25 minutes.

Certain precautions are necessary. Both operators must work in unison: care is needed here, especially when the syringes are being emptied, because of the less resistance on the exsanguinating side. If an air bubble is seen in the glass Y-piece the transfusion must be stopped by both operators at once and the bubble removed. The rubber connexions between the Y-piece and the syringes must be long enough to prevent any pull on, and possible breakage of, the $\mathrm{Y}$-piece (several spare Y-pieces are sterilized in case this happens, but so far they have not been needed). It is advisable to have a spare sterile syringe.

The advantage claimed for the method is the great saving of time. The disadvantage is that it requires two operators instead of one. 


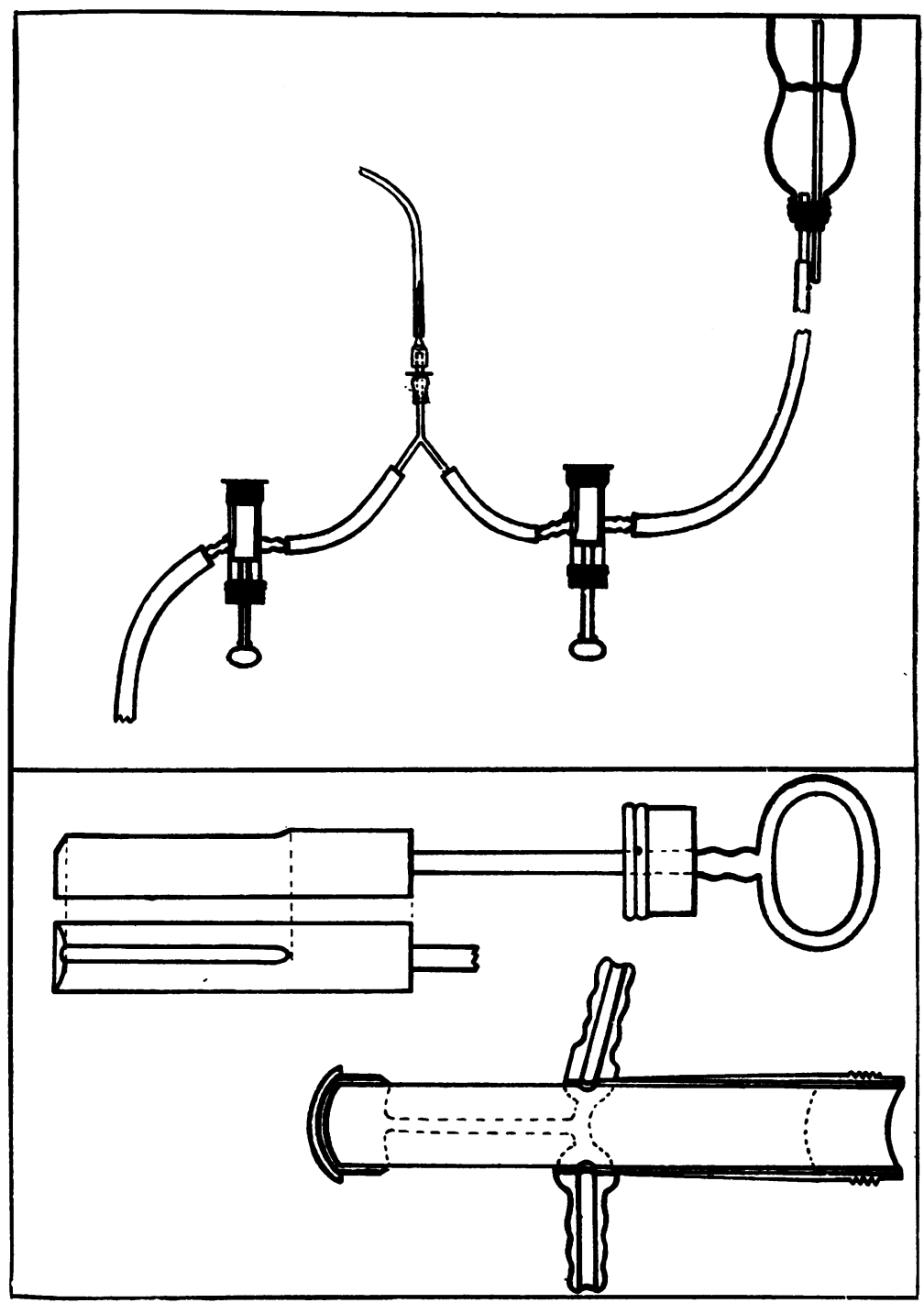

\section{Summary}

A method of carrying out exchange transfusion using two syringes is described. Certain precautions are noted.

[A possible criticism of this method is that the size of the syringe $(5 \mathrm{ml}$.$) is too small$ in relation to the dead space in the tubing and catheter. The exchange obtained with a small syringe is less effective ; in particular the advantage of the first withdrawal with a large syringe (wholly infant's blood) is lost. In practice, however, Dr. Barlow removes $25-30 \mathrm{ml}$. of infant's blood without transfusing and ends up with $35-40 \mathrm{ml}$. of blood without exsanguination.-ED.] 